\title{
Resistencia obrera y violencia patronal en el "Uruguay feliz" de los años 50: la huelga en Ferrosmalt
}

\author{
Pablo Ferreira \\ UDELAR, Uruguay \\ pablo.ferreira2311@gmail.com
}

\section{Introducción}

El 24 de abril de 1955 fueron despedidos 158 trabajadores de la empresa Ferrosmalt, uno de las más importantes establecimientos metalúrgicas del Uruguay, que se dedicaba a la fabricación de electrodomésticos. La empresa era una sociedad anónima de origen local que en los años previos había vendido parte de su capital accionario a la holandesa Philips. ${ }^{1}$ Los despidos desataron un enfrentamiento entre el sindicado y la patronal, que implicó una larga huelga en la empresa, extendida luego al conjunto de la industria metalúrgica. Durante el conflicto se exacerbaron los niveles de violencia, en especial a partir de que la patronal comenzó a contratar rompehuelgas y a organizar su traslado en camiones protegidos por personal armado y con custodia policial. En agosto la policía detuvo y llevó a prisión a varios obreros en huelga, luego de un enfrentamiento con quienes seguian trabajando y con el personal armado. El 17 de septiembre, en un nuevo episodio que involucró a los conductores de los camiones, a huelguistas y vecinos de la zona, fue asesinada María del Carmen Díaz y heridos varios vecinos.

El conflicto en Ferrosmalt y la violencia posterior admiten diversas miradas. Por un lado, permiten analizar las tensiones surgidas por el proceso de cambio iniciado en la empresa a partir de la aplicación de los llamados "métodos de productividad" y los intentos de reducir el poder del sindicato. En este aspecto es interesante cómo se articuló el discurso innovador de la productivdad con el mantenimiento de prác-

1. Empresa fundada en 1891 por el ingeniero Gerard Philips para producir lámparas incandescentes. En la década de 1920 comenzó la producción de electrodomésticos y la instalación de filiales en otros países europeos y en los Estados Unidos. Durante la Segunda Guerra Mundial inició su expansión en América Latina.

(Archivos, año V, nº 9, septiembre de 2016, pp. 139-158) 
ticas tradicionales de control sobre los trabajadores. Por otra parte, el episodio permite analizar las formas de violencia política imperantes en el tantas veces idealizado "Uruguay feliz" de los años 50. Deja entrever las tensiones al interior del batllismo, sector politico por entonces en el gobierno, que apostó a un modelo de desarrollo basado en la expansión del mercado interno y la conciliación entre capital y trabajo, pero que debió enfrentar cambios económicos que hicieron dificil sostener tal propuesta. Finalmente, permite analizar los vínculos del sindicato con el territorio y con otras organizaciones sociales, las formas en que se tramitó el enfrentamiento con la patronal y el accionar de diversos mediadores políticos.

A nivel metodológico se optó por reducir el objeto, procurando una mirada a ras del suelo, sobre un sindicato y un conflicto acotado, a los efectos de apreciar dimensiones que escapan al análisis de larga duración. ${ }^{2}$ La investigación se basó en diversas fuentes: libros que rescatan las memorias de dirigentes sindicales, ${ }^{3}$ prensa, ${ }^{4}$ entrevistas y trabajo de archivo. ${ }^{5}$ Se procuró en tal sentido cruzar el mayor número de fuentes a los efectos de ampliar la perspectiva de análisis, aunque priorizando la mirada sindical del conflicto.

\section{Tormentas en el "Uruguay feliz"}

En Uruguay, el periodo que transcurre entre la segunda posguerra y el final de la década de 1950 suele ser recordado como una etapa

2. Desde los años 60 varios trabajos han abordado la trayectoria de conjunto del movimiento sindical uruguayo en el periodo que aborda este artículo (véase Rodríguez, 1966; D’Elía, 1969; Errandonea y Costábile, 1969; Alfonso, 1970; Turianski, 1973; Sala y Landinelli, 1984; Cores, 1989). De forma reciente, los trabajos de Rodolfo Porrini (2005) avanzaron en una perspectiva de análisis que toma por objeto las transformaciones en la clase trabajadora y desde allí analiza su vínculo con el mundo del trabajo y las organizaciones sindicales. Han sido escasos, sin embargo, los trabajos que abordan conflictos específicos como el caso que aquí se presenta. En esa linea podemos destacar los trabajo de Graciela Sapriza (1993) sobre la huelga de trabajadoras en Juan Lacaze en 1913, de Rodolfo Porrini (2005: 251-327) sobre la huelga frigorífica de 1943, y de Isabel Wschebor y Ariel Soto (2004) sobre la huelga metalúrgica en 1950.

3. Masi (1989) y Mendiondo (s/f).

4. Fueron revisados el diario Justicia (afin al Partido Comunista), El Día (del sector conservador del Partido Colorado batllista) y los semanarios El Sol (Partido Socialista) y Marcha (independiente). Para un período anterior fue revisado el mensuario Clase Obrera (de la Agrupación Socialista Obrera).

5. Se revisó el archivo de la Unión de Trabajadores del Metal y Ramas Afines (UNTMRA) y las cajas provenientes del archivo Luis Batlle, que integran el fondo Archivos Particulares del Archivo General de la Nación, Uruguay. 
de prosperidad económica, estabilidad democrática y avance en las reformas sociales. Esta imagen, instituida por el elenco gobernante de entonces, se afirmó en el contraste con los países vecinos (en especial con Argentina) y con el ciclo autoritario que había vivido el país en los años 30. Posteriormente, el "Uruguay feliz" será evocado como antítesis de las convulsionadas décadas de los 60 y 70 . La perdurabilidad de este relato se explica también en la escasa producción historiográfica que aborda el periodo, lo que hace dificil se critique, matice o complemente esta mirada. ${ }^{6}$

En esos años, Uruguay estuvo gobernado por el Partido Colorado, concretamente por el ala reformista que reivindicaba el legado de José Batlle y Ordoñez. ${ }^{7}$ Los "batllistas" retomaron el poder en 1946 y se mantuvieron en el gobierno hasta 1959. Su antagonista fue el Partido Nacional, liberal en lo económico y conservador en materia social, liderado por Luis Alberto de Herrera. Otros grupos politicos menores que integraban el sistema político uruguayo eran las vertientes no batllistas del Partido Colorado, el Partido Nacional Independiente, la Unión Cívica y los partidos de izquierda, comunistas y socialistas.

En el plano económico, el país vivió un ciclo expansivo en que se combinaron el incremento de la demanda externa de sus productos primarios con el crecimiento industrial. El historiador Germán D'Elía (1982: 27) refiere a un ciclo de "desarrollo acelerado" iniciado tras la segunda guerra y que empezó a dar señales de agotamiento a mediados de los 50. Para ese entonces las condiciones externas variaban rápidamente, Europa se había recuperado de los efectos de la guerra, disminuía la demanda y el precio de los principales productos de exportación del país, elevándose a su vez el precio de los insumos que requería el sector industrial. La baja rentabilidad del sector agropecuario y las dificultades de la industria aumentaron las disputas entre los sectores empresariales, se incrementó la presión sobre el Estado y también sobre los sectores populares.

El proceso de industrialización vino acompañado de cambios en la clase trabajadora uruguaya. Rodolfo Porrini (2005: 8-9) ha estudiado la manera en que ésta se transformó de "algo amorfo e indefinido -como pareció existir en los 30- en una fuerza social, visible, con acciones intensas, que conmovieron a la sociedad uruguaya". Confluyeron en este proceso varios factores. Hubo un crecimiento cuantitativo de los trabajadores fabriles debido a la mayor ocupación de mano de obra por las industrias, continuó la inmigración proveniente del exterior y creció

6. Visiones de conjunto sobre el período en D’Elía (1982) y Ruiz (2007).

7. José Batlle y Ordoñez fue dos veces presidente del Uruguay (1903-1907 y 1911-

1915) y máxima figura del Partido Colorado hasta su muerte en el año 1929. 
la originada en las zonas rurales. A su vez se aceleró la incorporación de la mujer y los jóvenes al mercado laboral. Por otra parte, la ley de Consejos de Salarios aprobada en 1943, al hacer obligatoria la negociación por grupo de actividad, estimuló la coordinación entre sindicatos de un mismo sector y la formación de nuevas organizaciones.

A inicios de la década de 1950 el mundo sindical montevideano poseía una gran riqueza en sus vertientes ideológicas. La central sindical más importante era la Unión General de Trabajadores (UGT), creada en 1942 y liderada por dirigentes afines al Partido Comunista. Por otra parte, existía una segunda corriente de sindicatos que se denominaban "autónomos" en referencia a su no integración a las centrales existentes. Si bien eran una expresión inorgánica y diversa, tendieron a una progresiva articulación en el periodo. ${ }^{8}$ Una tercera vertiente era el "sindicalismo libre", que contó con el apoyo del Departamento de Estado de los Estados Unidos y que en 1951 se organizó en la Confederación Sindical del Uruguay (CSU), integrando a un número importante de sindicatos.

Desde fines de los años 40 se dieron importantes luchas sindicales en el marco de las negociaciones salarias. Desde las patronales industriales existía la percepción de que la legislación social había avanzado muy rápido y que se imponía un freno y, en la medida que las alianzas políticas lo hicieran posible, un retroceso. Una primera ofensiva se gestó durante el efimero gobierno de Tomás Berreta en 1947. Un segundo momento de fuerte conflictividad se extendió entre 1951 y 1952 donde se dieron acciones sindicales de importancia que generaron como respuesta gubernamental la imposición de "medidas prontas de seguridad" en marzo y septiembre de $1952 .{ }^{9}$ Estas acciones mostraron la capacidad de acción de los sindicatos, pero también el poder de presión de los grupos empresariales, que obtuvieron la aplicación de medidas orientadas a limitar el accionar sindical, incluyendo la detención de dirigentes y su traslado a cuarteles militares en el interior del país (Cores, 1989: 214-215).

8. Los llamados "gremios solidarios" fueron expresión de esa convergencia y representaron la coordinación para la acción reivindicativa de diversos sindicatos "autónomos". Sobre las vertientes del sindicalismo uruguayo en el período véase Cores (1989: 125 y ss.)

9. Las medidas prontas de seguridad son una prerrogativa constitucional que tiene el Poder Ejecutivo uruguayo desde la primera Constitución de 1830. Permiten disponer medidas excepcionales que pueden poner en suspenso el estado de derecho "en los casos graves e imprevistos de ataque exterior o conmoción interior", debiendo dar cuenta inmediata a la Asamblea General. Sobre su aplicación véase Iglesias (2011). 


\section{La organización sindical de los trabajadores metalúrgicos}

Desde mediados de la década del 30 la industria metalúrgica tuvo un importante crecimiento. En 1941 se constituyó el Sindicato Único de la Industria Metalúrgica (SUIM), que integró trabajadores que se dedicaban a actividades diversas, algunas todavia vinculadas al mundo tradicional de los oficios, y otros que ya tenían los perfiles del obrero industrial moderno. El nuevo sindicato fue fundador de la UGT y tuvo entre sus principales dirigentes a militantes del Partido Comunista.

La ley de Consejos de Salarios de 1943 influyó en la dinámica del joven sindicato. Imponía la negociación salarial tripartita, con participación de delegados de las patronales, los trabajadores y el Estado. Ello obligaba a trabajar para la elección de delegados sindicales, preparar la estrategia de negociación y finalmente generar medidas de presión para lograr los objetivos propuestos. Todo ello estimuló la vida sindical y la institucionalizó. Por otra parte, generó la oposición de militantes de orientación anarquista y trotskista que consideraban que la ley paralizaba la lucha de clases y conducía a la organización sindical hacia el reformismo. Algunos de ellos, junto a sindicatos de empresas que no se habían integrado al SUIM, conformaron en 1944 la Federación Obrera Metalúrgica del Uruguay (FOMU) que se mantuvo como "autónoma". En el nuevo sindicato fue ganando protagonismo la Agrupación Socialista Obrera (ASO), grupo político escindido del Partido Socialista que tuvo como uno de sus referentes a Gerardo Cuesta, por entonces trabajador metalúrgico en la empresa Pesce \& Simeone. La FOMU se caracterizó por una crítica sistemática a la estrategia sindical comunista a la que acusaba de subordinar los intereses proletarios a las necesidades del Estado soviético.

Si bien los Consejos de Salarios fueron el motivo de la escisión, generaron luego una dinámica de conflictos que operó como incentivo para la unidad. Las huelgas metalúrgicas de 1946 y 1950 fueron experiencias importantes en el acercamiento entre ambos sindicatos. En especial, la huelga de 1950 marcó un hito trascendente al ubicar a ambos sindicatos enfrentando a las patronales que no querian cumplir con el pago retroactivo de lo acordado en los Consejos de Salarios. Como señalan Isabel Wschebor y Ariel Soto (2004: 96), estas movilizaciones implicaron "el triunfo de una forma de concebir la negociación con las patronales en los marcos legales establecidos por el Estado".

En 1952 se iniciaron contactos formales tendientes a lograr la unidad entre ambos sindicatos. En ellas participaron dirigentes de SUIM, de FOMU y también de la Asociación Personal de Talleres (APTA), un pequeño sindicato que agrupaba a trabajadores carroceros y mecánicos. 
A lo largo de 1953 se dieron movilizaciones conjuntas y se avanzó en la elaboración de un plan de trabajo para la unificación, sobre la base de la discusión y resolución en un congreso, de los puntos que enfrentaban a los dirigentes de ambos sindicatos. El "Congreso de la Unidad", tal como se lo llamó posteriormente, estuvo precedido por la realización de asambleas de base que discutieron el temario y eligieron sus delegados. En cada asamblea podían concurrir como veedores delegados de los otros dos sindicatos; tenían un quórum mínimo para sesionar y elegían delegados de acuerdo al número de obreros que tuviera cada empresa. Según recordaba el dirigente del SUIM Rosario Pietraroia, se realizaron más de trescientas asambleas de fábricas durante tres meses (Masi, 1989: 90). El principal punto de discordia era la integración del nuevo sindicato a la UGT, lo que era defendido por el SUIM y por APTA y rechazado por la dirigencia de FOMU.

El congreso, reunido en octubre de 1953, dio origen al Sindicato Único de Metalúrgicos, Mecánicos y Afines (SUMMA). Políticamente fue un triunfo de la línea comunista que logró imponerse en las votaciones y, por ende, que el nuevo sindicato aprobara la afiliación a la UGT e incorporara en su programa la "lucha por la paz" y la "defensa de la industria nacional", puntos que eran rechazados por FOMU. Asimismo, se eligió una dirección colectiva integrada por los principales referentes de los sindicatos prexistentes: Rosario Pietraroia del SUIM, Gerardo Cuesta de FOMU y Pedro Toledo de APTA. El triunfo del Partido Comunista se completó un año después al lograr la afiliación de Gerardo Cuesta. ${ }^{10}$

\section{El conflicto en Ferrosmalt}

La empresa Ferrosmalt estaba ubicada en La Teja, barrio obrero ubicado en el oeste de la ciudad de Montevideo. Jurídicamente era una sociedad anónima que había enajenado parte de su capital accionario a manos de la empresa holandesa Philips. Esta última actuaba a nivel internacional formando un cártel con la norteamericana General Electric y juntas habian avanzado sobre América Latina adquiriendo una parte de la empresa argentina SIAM.

Al mando de Ferrosmalt se mantuvo parte importante del directorio y el equipo gerencial anterior encabezado por el octogenario José Serrato. ${ }^{11}$ Los nuevos accionistas buscaron innovar en el sistema de

10. Sobre la crisis de la Agrupación Socialista Obrera y la afiliación de Gerardo Cuesta al Partido Comunista véase Leibner, 2013.

11. El Ingeniero José Serrato además de ser accionista y gerente de Ferrosmalt tenía participación en el capital accionario de empresas arroceras, en Cristalerías del Uruguay, en la empresa Alpargatas y en el Banco Montevideo. Además habia tenido 
trabajo a partir de los llamados "métodos de productividad" que eran una expresión tardía de la matriz fordista. Una de las primeras acciones implementadas durante 1954 por los técnicos llegados del extranjero fue la elaboración de un sistema de puntajes orientado a incrementar el ritmo de producción y a incentivar la competencia entre los trabajadores. Cumplido el objetivo inicial, al año siguiente se decidió reducir el personal de planta. ${ }^{12}$

El domingo 24 de abril de 1955, 158 trabajadores fueron visitados en sus domicilios por personal administrativo de la empresa que los notificó de la resolución de prescindir de sus servicios. Se pretendía además entregarles un monto de dinero a modo de indemnización lo que fue rechazado de forma mayoritaria al considerar que los despidos eran injustificados. ${ }^{13} \mathrm{Al}$ elegir los trabajadores despedidos, la empresa no tuvo en cuenta los puntajes obtenidos el año anterior y tomó un criterio que privilegió sus antecedentes sindicales. Entre los despedidos estaban casi todos los integrantes del comité de empresa, dirigentes de trayectoria, que habian participado de las huelgas de 1946 y 1950 y del reciente proceso hacia la unidad sindical de los metalúrgicos.

Comenzaba un largo conflicto. El 27 de abril, ante la agitación existente entre el personal, la empresa cerró sus puertas, realizando lo que los trabajadores denunciaron como un lockout patronal, que se extendió hasta el 2 de mayo. ${ }^{14} \mathrm{El}$ retorno a las tareas estuvo marcado por una gran tensión. El sindicato logró organizar un nuevo comité de empresa e implementar un conjunto de paros parciales con el objetivo de reclamar el reintegro de los despedidos. Al mismo tiempo, se realizaron gestiones ante la Cámara Metalúrgica y el Parlamento que dieron resultados positivos. Cuando se había logrado la instalación de una comisión para mediar en el conflicto, la empresa despidió a 82 nuevos trabajadores. El 21 de junio la comisión de Legislación de Diputados censuró públi-

una dilatada carrera política vinculada al Partido Colorado. Fue diputado, ministro de Hacienda entre 1904 y 1906, ministro de Interior en 1911, presidente de la República entre 1923 y 1927, integrante del Consejo de Estado de 1942 y canciller de la República entre 1943 y 1945. Luego había ocupado la presidencia de la Cámara Metalúrgica a la que había renunciado durante la huelga de 1950. En 1955 ocupaba la presidencia de la Unión Industrial del Uruguay.

12. "Al desnudo los métodos yanquis de 'productividad' en Ferrosmalt: despidos en masa y represión", en Justicia, 2 de septiembre de 1955, p. 3.

13. Documento del Consejo Directivo del SUMMA, agosto de 1957, "La Lucha del Gremio metalúrgico en defensa de la Unidad Sindical desde el 24 de abril de 1955 hasta el presente y la actitud asumida por la CSU en contra de los intereses de los trabajadores", Archivo UNTMRA (en adelante, Documento...).

14. "El Comité de Huelga de Ferrosmalt a la opinión pública y al Gremio", en Justicia, 12 de septiembre de 1955, p.3. 
camente el accionar de la empresa al constatar "la persecución sindical en los despidos" y comenzó a trabajar en una fórmula, vía proyecto de ley, para la reposición de los despedidos. ${ }^{15}$

Ante la postura asumida por la empresa, el personal declaró la huelga por tiempo indeterminado el 7 de julio, amenazando con llevar la medida al conjunto de la industria metalúrgica. De 600 trabajadores que tenía en planilla la empresa, solo 41 habrian continuado trabajando según la versión del comité de huelga. ${ }^{16}$

\section{La violencia se instala}

La situación se hizo más tensa cuando la empresa contrató nuevo personal, "rompehuelgas" o "krumiros", según expresión utilizada en la época. Juan Carlos Fontella recuerda que la huelga "conmocionó al barrio", "porque los muchachos que trabajaban ahí, vivian en la zona". En su familia, que opera como ejemplo de muchas otras, trabajaban su hermano y su cuñado en la planta. ${ }^{17}$ Los "krumiros" debian enfrentar, al entrar y salir de la fábrica, el repudio de los vecinos que se traducía en insultos, pedreas y otras agresiones. En ese marco, la empresa comenzó a organizar su traslado en camiones. Los recogían en diversos puntos de la ciudad, los ingresaban a la fábrica cubiertos con toldos y los sacaban de la misma forma.

El 20 de agosto se produjo un enfrentamiento de mayor entidad que terminó con varios obreros detenidos. El sindicato habia resuelto realizar una concentración en las cercanías de la fábrica para intentar disuadir a los trabajadores no plegados a la huelga. El transporte en camiones se realizaba desde hacía varias semanas con custodia policial. Según los testimonios recogidos por el ministro del Interior Francisco Gamarra, al acercarse los camiones se generaron pedreas y hubo un enfrentamiento entre obreros "a trompadas". Según Gamarra, desde la policía se realizaron disparos al aire con el objetivo de disuadir a los huelguistas (Diario de Sesiones de la Cámara de Senadores [en adelante, DSCS], 1956: 327). Éstos, por su parte, destacaron el accionar represivo de la policía tanto en el episodio como en otros hechos previos. Las denuncias recaían sobre el comisario Regueiro de la seccional $20^{\mathrm{a}}$ de Montevideo. El 7 de septiembre una comisión de la Cámara de Diputados convocó al ministro del Interior y en esa instancia el diputado batllista Zelmar Michelini presentó diversas denuncias, señalando que Regueiro

\section{Documento..., 1957.}

16. "El Comité de Huelga de Ferrosmalt a la opinión pública y al Gremio", en Justicia, 12 de septiembre de 1955, p.3.

17. Entrevista a Juan Carlos Fontella, noviembre de 2012. 
"ha[bía] sido acusado de estar sembrando el terror en numerosas familias de obreros". Lo acusaba de tolerar que "elementos vinculados a la patronal estén armados". Por su parte, el diputado del Partido Nacional Antonio Suárez Ponte denunció que los huelguistas eran revisados y se les impedía andar en grupos. Al mismo tiempo señalaba haber recibido "denuncias de que algunos obreros que están trabajando usaron armas, y que en algunas circunstancias hasta en presencia de la policía”. Suárez Ponte hacía referencia a una conversación mantenida con Regueiro donde éste le señaló "que a los que trabajaban como a los que no trabajaban, a todos les daba la autoridad el porte de armas" (DSCS, 1956: 323).

El senador José Pedro Cardoso denunció en el Parlamento, en noviembre de 1955, que diversos testigos le habian señalado "que veían, cada día, cómo los rompehuelgas entregaban en la portería cuchillos, cachiporras y revólveres". El senador se preguntaba cómo era posible que se proveyeran de "revólveres esos hombres que estaban trabajando como jornaleros". La acusación recaía sobre la patronal y sobre la policia "que recogía todos los dias a los que trabajaban en la empresa para acompañarlos al retirarse" (DSCS; 1956: 325).

A inicios de septiembre el conflicto ingresó en una etapa crítica. Dos meses de huelga, innumerables gestiones infructuosas y un clima de violencia en aumento marcaban la coyuntura. El sindicato tenía alrededor de diez obreros detenidos y se estaba preparando para el 6 de septiembre un paro general que incluía tanto a sindicatos "autónomos" como a la UGT. De no haber soluciones, estaba previsto el inicio de la huelga general en toda la industria metalúrgica. El punto que impedía alcanzar una salida era la negativa de la empresa a reincorporar a veintisiete dirigentes sindicales. El sindicato buscó desde el inicio quebrar el frente patronal, propiciando el conflicto de intereses entre el directorio de Ferrosmalt y el resto del empresariado metalúrgico. Se destacó en el discurso de sus voceros la gradualidad de las medidas adoptadas, procurando dejar en claro que el sindicato no quería ir a la huelga y entendia que la misma generaría dificultades a numerosos industriales que también padecían los efectos de la crisis económica. ${ }^{18}$

El 8 de septiembre dio inicio la huelga general metalúrgica. En esa jornada se hizo una importante asamblea en la sala del club Boston, una conocida institución deportiva que había sido anfitriona del congreso fundacional del SUMMA. Rosario Pietraroia, secretario general del sindicato, intervino en la asamblea definiendo el conflicto como "la batalla por las libertades sindicales, por el derecho de organización [y] por la

18. "La Philips, Serrato y el gobierno serán los responsables", en Justicia, 4 de septiembre de 1955, p.3. 
defensa de la industria nacional contra la voracidad de los monopolios extranjeros". Por otra parte, discutió el argumento patronal que sostenía haber cumplido la ley al ofrecer una "indemnización por despido", señalando que la ley no se había hecho para que "los capitalistas la usaran de instrumento de represión contra dirigentes sindicales". ${ }^{19}$

Las muestras de apoyo recibidas por el sindicato fueron importantes. Hubo aportes económicos de otros sindicatos, apoyo de la Federación de Estudiantes Universitarios y en algunos barrios, como La Teja y Paso de la Arena, se constituyeron "comités" de ayuda a las familias de los trabajadores. ${ }^{20}$ El Día, vocero de la lista catorce, fracción conservadora del batllismo, explicaba la solidaridad barrial (que reconocía) como expresión de temor. Según un editorial, que dice tomar como base la carta de un lector, sería

el temor de exponer a los suyos a peligrosas venganzas, el retroceso ante la segura perspectiva de ver su casa marcada, el miedo de quedar una buena noche "tirado en medio de una calle", víctima de delincuentes con causa abierta que actúan al servicio de las directivas sindicales soviéticas [...] son causa de que, comerciantes adversos al comunismo, alimenten las "ollas" que se organizan en locales de gremios en conflicto, y por su intermedio a verdaderas pandillas de elementos asociales que los dirigen. ${ }^{21}$

Finalmente, tras arduas negociaciones la Comisión de Legislación de Diputados alcanzó un proyecto de ley que reconocía que los despidos eran contrarios al derecho de sindicalización y obligaba a la empresa a reincorporar a los obreros. Se establecía que los trabajadores comprendidos en la ley gozarian de los salarios que les correspondian desde la promulgación de la misma y no podrían ser separados de sus cargos antes de seis meses, salvo por causa fundada, que debería probar el empleador en el Instituto Nacional del Trabajo. ${ }^{22}$

El 13 de septiembre la Cámara de Diputados aprobó en general el proyecto, pero luego la discusión volvió a instalarse al votarse su arti-

19. "La lucha de los Metalúrgicos. Derrotará a Serrato y obligará al gobierno a actuar", en Justicia, 9 de septiembre de 1955, p.1.

20. Véase "Paso de la Arena: nuevo baluarte solidario con la huelga de Ferrosmalt" en Justicia, 13 de septiembre de 1955, p. 3 y "¡Así se forja el triunfo en Ferrosmalt! Víveres, dinero en río continuo, hace llegar la solidaridad popular al local de la calle Laureles", en Justicia, 25 de septiembre de 1955, p.2.

21. "Sobre libertades sindicales", en El Día, 15 de septiembre de 1955, p.7.

22. "Puede ser planteado en la sesión de hoy como grave y urgente", en Justicia, 12 de septiembre de 1955, p.4. 
culado. Las dificultades estaban al interior del Partido Colorado y eso podía explicarse, tanto por su alto fraccionamiento (que enfrentaba a sectores conservadores y progresistas), como por el peso que tenían los industriales en su interna. En ese marco, cinco legisladores de la lista quince presentaron un nuevo proyecto que permitía al empresario optar entre el reintegro del dirigente sindical o el pago de una indemnización doce veces mayor a la estipulada por despidos comunes. ${ }^{23}$ Finalmente la sesión quedó sin quórum y no se pudo aprobar ninguna de las propuestas.

\section{E1 "crimen de La Teja"24}

A las 15 horas del sábado 17 de septiembre salieron de Ferrosmalt seis camiones que conducian a dos centenares de obreros que trabajaban en la empresa, protegidos por efectivos policiales. Los camiones se dirigian por la calle Celestino Bauzá en dirección a Carlos María Ramírez, una de las principales vías de salida hacia el centro de la ciudad. Según diversos testimonios, ante los insultos de los vecinos a la altura de la calle Gregorio Camino, comenzaron a efectuarse disparos desde los camiones. Algunos testigos aseguran que "hubo premeditación" y que "los camiones que conducian a los elementos armados disminuyeron la marcha". ${ }^{25}$

Para Francisco Gamarra, ministro del Interior, no estaba claro quién comenzó a disparar. Según expresó en una comparecencia ante la Cámara de Senadores, "los que iban en los camiones manifestaron que tan pronto como se sintió una extraordinaria pedrea se tiraron al piso para salvarse. Sintieron también los disparos de revólver y alguno de ellos declara que vio a uno, de apellido Corujo, que hacía fuego desde los camiones" (DSCS, 1956: 328).

A la altura de la calle Molina, un disparo hirió gravemente a María del Carmen Díaz y de forma más leve a Piñeyrúa de Falero y su hijo. María del Carmen Díaz tenía 42 años y era madre de ocho hijos. Era la suegra de Mario Pérez, presidente del comité de huelga de Ferrosmalt e

23. "El Senado debe sancionar. El Proyecto sobre el conflicto metalúrgico", en Justicia, 23 de septiembre de 1955 , p. 2 . La lista quince era la vertiente reformista del batllismo, liderada por Luis Batlle. Sobre la trayectoria política y la ubicación ideológica de este sector véase Ferreira (2014: 105-124).

24. Esta expresión fue utilizada reiteradamente en el diario Justicia para referir a los sucesos del 17 de septiembre.

25. "Testigos presenciales denuncian el crimen de las bandas armadas de Serrato y la complicidad policial", en Justicia, 19 de septiembre de 1955, p. 3. 
integrante del consejo directivo del SUMMA. ${ }^{26}$ Díaz se habría desangrado en la calle durante diez minutos sin que los vecinos lograran parar un patrullero para que la recogiera. Según testimonios de prensa, estos "pasaban a toda velocidad y hacian disparos". Finalmente, uno se detuvo y "la herida fue introducida en el coche brutalmente. Arrancó con la puerta abierta y Maria del Carmen Díaz fue despedida violentamente a la calzada", generándose dudas entre los testigos, respecto a si la causa final de la muerte fue por el disparo o por el golpe. ${ }^{27}$

Blanca Falero, hija y hermana de dos de los heridos, narró que tras la caída de Díaz se acrecentó la indignación del vecindario. En ese momento "la policía golpea a machetazos, hiriendo a un vecino en un hombro y dispara contra los vecinos, hiriendo en el brazo a Ruben Villarreal". A partir de ese momento se implantó una suerte de "estado de sitio" y "decenas de patrulleros recorr[ía]n las calles a toda velocidad". ${ }^{28}$

Particularmente interesante es la crónica que realiza el diario $\mathrm{El}$ Día. Este periódico respondía a la vertiente conservadora del batllismo y había tenido una línea editorial crítica respecto a la huelga, oficiando de vocero de la Cámara Metalúrgica y del directorio de Ferrosmalt. El episodio no ocupó los titulares y fue informado en la sección de "policiales", sacándole su componente político e igualándolo con otros hechos de la llamada "crónica roja". Pese a ello, el cuerpo de la nota, además de utilizar las clásicas fuentes policiales, reproduce entrevistas a testigos que contradicen la línea editorial del diario. Es más, varios de estos testimonios fueron utilizados por el senador socialista José Pedro Cardoso en la comparecencia del ministro del Interior ante el Senado. Uno de los entrevistados, Pedro Worwk señaló que el chofer de uno de los camiones conducía el volante con su mano izquierda, mientras con la derecha "esgrimía un revolver, con el que realizó abundantes disparos". María de Castro, también vecina y testigo de los hechos señaló que los disparos provenian del tercer camión y que tras herir a Díaz su conductor "realizó una maniobra y se fue contra un árbol que estaba a dos o tres metros". El cronista de El Día señaló luego que en la comisaría, donde estaban retenidos los seis camiones, pudo apreciar que uno de los coches tenía roto el farol delantero izquierdo. ${ }^{29}$

26. "Policía. En un incidente entre obreros de Ferrosmalt y vecinos, fue muerta de un disparo una Sra. Además se registraron 3 heridos de bala", en El Día, 18 de septiembre de 1955, p. 11.

27. Ibíd.

28. "Vi caer a mi madre herida...", dice Blanca Falero, que presenció los hechos del sábado, señala la alevosa premeditación de los asesinos”, en Justicia, 20 de septiembre de 1955, p. 3.

29. "Policía. En un incidente entre obreros de Ferrosmalt y vecinos, fue muerta de 
El juez de instrucción realizó diversos interrogatorios y dispuso esa noche la libertad de todos los detenidos, con excepción de Ramón Corujo, identificado como autor de uno de los disparos, aunque las fuentes policiales del cronista puntualizaron "que fue tirando al aire". ${ }^{30}$ Pocos dias después Corujo fue puesto en libertad por falta de pruebas.

Dos meses después de los hechos se hizo presente en el Parlamento el ministro del Interior Francisco Gamarra, para informar sobre lo acaecido en Ferrosmalt. Su presencia había sido solicitada por el senador José Pedro Cardoso pero se había suspendido en varias ocasiones por falta de quórum. En la sesión del senado del 22 de noviembre, y tras una nueva postergación, Cardoso presentó el tema en la "hora previa", momento en que podian ser planteados asuntos fuera del orden del día. Enterado de que se discutian los hechos, el ministro se hizo presente y fue interrogado respecto a la pasividad policial. Señaló el ministro que producidos los disparos y el posterior enfrentamiento "si la policía hubiera descendido la batalla campal habria adquirido proporciones de desastre" (DSCS, 1956: 328). Las explicaciones no conformaron a Cardoso. No lograba entender cómo la policía que recogía todos los días a los que trabajaban en la empresa no sabía que iban armados. Se preguntaba: “¿Por qué la policía no detuvo enseguida a los camiones? ¿Cuál e[ra] el grado de complicidad de la autoridad policial?”. Según Cardoso, la protección policial a los trabajadores no plegados a la huelga "se transformó en la protección de un atentado criminal", configurando "una línea política" del gobierno. Culminó su intervención señalando la proyección futura de estos hechos al mencionar enfáticamente que "de esta siembra no sal[dria], por cierto, una buena cosecha" (DSCS, 1956: 326).

Tras los episodios, la policía se desplegó en el barrio impidiendo el tránsito en grupos de más de dos personas. Según testimonios que recogió $\mathrm{El} \mathrm{Sol}$, en las horas posteriores funcionarios de la seccional policial 19 fueron "a presionar a algunos vecinos interrogándolos sobre qué declaraciones efectuarian en caso que se determinara una investigación". Otros vecinos, que firmaron una declaración aparecida en la prensa, habrían recibido una citación de la policía de Investigaciones (Sección Inteligencia y Enlace) donde se les tomó declaraciones. ${ }^{31}$

un disparo una Sra. Además se registraron 3 heridos de bala", en El Día, 18 de septiembre de 1955, p. 11.

30. Ibíd.

31. "El conflicto de Ferrosmalt. Graves puntualizaciones sobre la arbitrariedad policial. Entrevista a Anselmo Dorta Rodríguez activista sindical y vecino de la zona", en $E l$ Sol, 29 de septiembre de 1955, p. 3. 


\section{Epílogos al conflicto}

En los dias siguientes se aceleraron las coordinaciones entre sindicatos y organizaciones estudiantiles para responder a los hechos con una medida unitaria de lucha. En este marco se aprobó un paro para el 27 de septiembre con una plataforma que incluía el "encarcelamiento de los criminales y sus instigadores", la intervención judicial del local de Ferrosmalt y una solución inmediata al conflicto metalúrgico. ${ }^{32}$

La dirección del SUMMA buscaba encauzar el conflicto, denunciando el "accionar criminal" de lo que llamaban la "banda de Serrato" y la complicidad policial, al mismo tiempo que se retomaban las negociaciones a nivel parlamentario. En el primer aspecto, el 19 de septiembre aparecía en la prensa un comunicado del SUMMA denunciando la complicidad de la empresa en los hechos. En él se señalaba que a poco de iniciada la huelga se habian organizado bandas armadas con el fin de "intimidar y agredir a los huelguistas", asimismo se identificaba al representante de la Philips en Uruguay, al jefe de serenos y al jefe del personal, como los organizadores de las bandas. También se denunciaba que el frente del domicilio de Mario Pérez (donde vivía Carmen Díaz) había sido "alquitranado por elementos a sueldo de la patronal". ${ }^{33}$

Por otro lado, se buscaba sumar fuerzas al proyecto votado en Diputados. Desde la Unión Industrial, José Serrato convocaba a formar un movimiento de impugnación al proyecto, al que consideraba negativo por no reglamentar la actividad sindical. ${ }^{34}$ La Cámara Metalúrgica expresaba una posición más ambigua, respaldando a la empresa pero buscando una rápida salida al conflicto. ${ }^{35}$ Pocos días después, José Serrato presentó renuncia a la presidencia de la Unión Industrial, hecho que fue valorado como un triunfo por el sindicato.

Comenzó en esos días a actuar una comisión mediadora designada por el Consejo Nacional de Gobierno, el Poder Ejecutivo de la época. La primera fórmula propuesta establecía que Ferrosmalt retomaria, a su elección, nueve de los veintisiete obreros que se habían negado a cobrar la indemnización. El resto de los despedidos ingresarian en otras empresas, conservando categorias y antigüedad, y solo por causa grave podrian ser despedidos. Se gestionaría además un préstamo de 30 jornales para

32. "Los sindicatos y estudiantes exigen solución a la huelga y castigo a los criminales", en Justicia, 19 de septiembre de 1955, p. 3.

33. "Crimen premeditado", en Justicia, 19 de septiembre de 1955, p. 2.

34. "Remitido. El Movimiento del Trabajo Nacional impugnando el proyecto sobre despidos", en Marcha, 23 de septiembre de 1955, p. 3.

35. Véase "Remitido. La Cámara Metalúrgica de la Unión Industrial Uruguaya a los patronos y obreros metalúrgicos", en El Día, 17 de septiembre de 1955, p. 11. 
los obreros de Ferrosmalt y de 15 para el resto de los metalúrgicos que participaron de la huelga. El 25 de septiembre esta fórmula fue discutida por los comités de base del SUMMA que consideraron inaceptable el número de reintegros y que los mismos sean decididos por la empresa. La propuesta sindical era que los reintegros se hicieran por antigüedad. Asimismo, se solicitaba que el Ejecutivo convocara a los Consejos de Salarios y se comprometiera a enviar un proyecto de ley para conceder una pensión a los hijos de María del Carmen Díaz. ${ }^{36}$

La comisión mediadora siguió manteniendo reuniones con la Cámara Metalúrgica, el directorio de Ferrosmalt, la dirección del SUMMA y el Consejo Nacional de Gobierno. El 29 de septiembre la empresa aceptó reponer a 14 de los 26 despedidos, pero manteniendo el criterio de que sería ella la que decidiría a qué obreros reintegrar. ${ }^{37}$ Finalmente, tras 83 dias de huelga en la empresa y 23 en el conjunto de la industria, los trabajadores metalúrgicos aprobaron la propuesta y votaron el levantamiento de la huelga. La prensa comunista brindó un amplio espacio a esta última asamblea, valorando la fórmula aprobada como un "triunfo" del sindicato. ${ }^{38}$

La violencia se reinstaló de forma casi inmediata. Los obreros que participaron de la huelga y los que habian trabajado fueron separados por turnos. El 5 de octubre, se produjo un enfrentamiento en el cambio de turno y fue detenido por realizar disparos Diego Ríos, un trabajador

36. "Los obreros Metalúrgicos tratarán hoy propuesta de la Comisión Mediadora. Se realiza la Asamblea General en el Boston", en Justicia, 26 de septiembre de 1955, p. 1.

37. "Los Metalúrgicos firmes hasta el triunfo", en Justicia, 29 de septiembre de 1955, p. 1.

38. La huelga en la empresa Ferrosmalt coincidió con un proceso partidario que adquiere para este relato particular trascendencia. El 14 de julio de 1955 se expusieron duras críticas en el Comité Ejecutivo del Partido Comunista del Uruguay (PCU) contra su secretario de Organización, Eugenio Gómez Chiribao, hijo del Secretario General, Eugenio Gómez. Se trataba, según el historiador Gerardo Leibner (2013: 190) de un orquestado "golpe de partido" que conduciria a un cambio trascendente en la dirección y orientación de la organización. Para septiembre estaba prevista la realización del XVI Congreso, donde se discutirian los hechos recientes, se definirian las nuevas orientaciones politicas esbozadas por las autoridades provisorias y se elegiria una nueva dirección. El congreso, que generaba una enorme expectativa entre los comunistas uruguayos, fue suspendido y se realizó una semana después de lo previsto a raíz del asesinato de María del Carmen Díaz. Es dificil evaluar cuánto impactaron las disputas internas del PCU sobre los principales dirigentes del SUMMA, que debieron liderar un dificil conflicto sindical y al mismo tiempo tomar posición y adaptarse al rápido viraje que gestaba su partido. Lo que parece claro, a partir de la compulsa de la prensa comunista, es que la "heroica" huelga de Ferrosmalt, conducida por algunos dirigentes de primera línea y afines a la posición renovadora, operó como un factor que permitía cerrar filas y contribuía a sobrellevar la crisis interna que el partido estaba viviendo. 
que no había participado de la huelga.$^{39}$ Los turnos se habían reducido a cinco horas y el sindicato denunciaba que los capataces pretendian lograr en ese tiempo la productividad de un jornal de ocho. ${ }^{40}$

A fines de 1956 se generó un nuevo conflicto que puso en discusión la manera en que se habia laudado la huelga el año anterior. En octubre la empresa Kraft-Imesa despidió a Mario Pérez, ex dirigente de Ferrosmalt, que había ido a trabajar a esa empresa luego de la firma del convenio. La situación era particularmente compleja ya que la empresa había esperado un año para despedirlo. El convenio de 1955 establecía que ningún obrero reincorporado podía ser despedido antes del año. Sin embargo, según la lectura que hacían los dirigentes del SUMMA, no estaba en el espíritu de lo acordado que pasado un año las empresas tuvieran libertad para despedir a sus trabajadores. Kraft-Imesa era además una de las pocas empresas donde el SUMMA no tenía una presencia sindical mayoritaria. Desde los años 40 había sido bastión de FOMU y, tras la unificación, había quedado en esa fábrica parte del pequeño núcleo de militantes que mantenían activa a la muy disminuida federación, que además se había afiliado a la CSU en $1956 .{ }^{41}$

En Ferrosmalt, el sindicato sufría los efectos de la huelga del año anterior y la salida de muchos de sus dirigentes. En ese marco la amenaza de una nueva huelga generó resistencias en parte de los trabajadores que constituyeron una comisión directiva de emergencia. Ésta impulsó la realización de un plebiscito que proponía no acatar propuestas de huelga provenientes del SUMMA. Obteniendo el aval de la mayoría de los trabajadores, la nueva comisión directiva constituyó el Sindicato Autónomo de Trabajadores de Ferrosmalt que pocos meses después se afilió a la CSU. De este modo, uno de los bastiones del SUMMA se desprendía del sindicato y se mantendría autónomo hasta finales de los años $60 .{ }^{42}$

39. Intervención del ministro del Interior Dr. Francisco Gamarra en la sesión de la Cámara de Senadores del 23 de noviembre de 1955, DSCS, tomo 211, p. 328.

40. "En Ferrosmalt resisten la llamada "productividad", en Justicia, 5 de enero de 1956, p. 3.

41. Documento..., 1957: 15.

42. Ibíd, p. 18. Si bien escapa a los objetivos del artículo, resulta pertinente destacar el silencio que guardan los relatos más "oficiales" del sindicato sobre los episodios de 1956. En la entrevista a Rosario Pietraroia realizada por Hugo Masi (1989), en el trabajo de Dari Mendiondo sobre Gerardo Cuesta y en los diversos textos de formación elaborados por el sindicato en los años 90, se destaca la huelga, se reivindica la figura de María del Carmen Díaz (existe un monolito en homenaje erigido por el sindicato y la Junta Departamental de Montevideo en un espacio libre cercano a donde se ubicaba la planta de Ferrosmalt) y se hace referencia al "triunfo" sindical en la huelga, cerrándose los relatos a fines de 1955. Dari Mendiondo, entrevistado para 


\section{Algunos apuntes finales}

Los estudios en clave micro, que aborden episodios puntuales de acción sindical, son escasos dentro de la historiografia uruguaya, siendo predominantes los enfoques que se mueven en un tiempo más largo, rescatando la historia de un sindicato o del "movimiento sindical" en su conjunto. El análisis micro no genera solamente una variación en las dimensiones de lo observado, sino que hace visible aspectos nuevos (Revel, 2005: 46). Exime al investigador de cierta tendencia a la búsqueda de continuidades, permitiendo reconstruir de manera más adecuada contextos que son siempre plurales y múltiples, haciendo posible acercarse al conocimiento del horizonte de expectativas de los protagonistas.

¿Qué aporta el estudio del conflicto en Ferrosmalt? En primer lugar, permite indagar sobre las formas en que el capital extranjero ingresó al sector industrial uruguayo en los años 50. En Ferrosmalt es interesante cómo se articularon varias facetas de este proceso: la compra de parte del capital accionario por una empresa multinacional, el mantenimiento del equipo directivo local, la pretensión de incorporar nuevas pautas de trabajo y finalmente la continuidad de las prácticas antisindicales tradicionales. El problema de la productividad, que no es otra cosa que la búsqueda de caminos para producir más utilizando menos recursos, y por ende, incrementando la tasa de ganancia, fue uno de los dilemas de la industrialización en América Latina. El caso permite ver la tensión entre estas iniciativas, las vias en que se proyectaron y las resistencias que generaron entre los trabajadores.

Otro aspecto que se esboza es el vínculo entre figuras clave del empresariado industrial local y el gobernante Partido Colorado. Una de las grandes apuestas del segundo ciclo batllista fue la industrialización. En consecuencia, más allá del discurso obrerista que ponía la "justicia social" como objetivo último, los empresarios industriales se constituyeron en parte importante de la base social del sector. Las idas y venidas

la investigación destacó, utilizando una imagen propia del gremio al que perteneció, que "la unidad votada en 1953 se "soldó" con la huelga en solidaridad con Ferrosmalt". Los hechos de 1956 los hemos reconstruido a partir de las escasas fuentes de época, en especial el documento ya referido elaborado por el Consejo Directivo del SUMMA en 1957. Esto permite reflexionar sobre la compleja relación entre las "memorias" sindicales y los procesos históricos concretos. En el caso del SUMMA (que a partir de 1961 pasó a llamarse Unión Nacional de Trabajadores del Metal y Ramas Afines) la concreción de la unidad de los trabajadores metalúrgicos es el gran eje articulador de la "memoria" sindical, un proceso al que se narra como progresivo, apoyado de forma unánime por los trabajadores y concretado a partir de la "visión estratégica" de los principales dirigentes de la época, todos ellos además militantes del Partido Comunista, grupo político que conserva hasta hoy el predominio en la dirección del sindicato. 
en la búsqueda de una salida negociada al conflicto en el Parlamento pueden ser leídas como expresión de las tensiones en la interna del sector y la capacidad, tanto de industriales como de trabajadores, de incidir sobre los legisladores.

Un tercer aspecto está relacionado con la violencia política y sus formas. La represión estatal sobre las capas medias politizadas en los años 60 generó un fuerte impacto y una sensación de ruptura con las prácticas politicas tradicionales que subsiste hasta el dia de hoy en el Uruguay. Sin embargo, las formas mucho más habituales de violencia sobre los sectores populares (en especial los obreros, pero también los trabajadores rurales) han tenido una visibilidad menor. El trabajo permite apreciar cómo el "Uruguay feliz" de los años 50 albergó prácticas cotidianas de violencia sobre estos sectores y sus organizaciones que estuvieron amparadas (y en ocasiones protagonizadas) por el Estado. ${ }^{43}$ En tal sentido, la investigación permite seguir buscando líneas de continuidad entre estas formas de violencia y las que surgieron en los años posteriores. De esa manera, aporta en la línea de ampliar el campo cronológico de los estudios sobre la violencia política y continuar reflexionando sobre las tensiones entre libertad y orden en tanto constitutivas de la democracia liberal uruguaya de las décadas previas a la última dictadura. ${ }^{44}$

\section{Referencias bibliográficas}

Alfonso, Pedro (1970), Sindicalismo y revolución en el Uruguay, Montevideo: Nuevo Mundo.

43. No existen trabajos académicos que aborden el accionar de los grupos armados por las patronales para enfrentar a los sindicatos, así como respecto de los llamados krumiros o rompehuelgas, cuya contratación es referida en las fuentes para diversos conflictos del período. El trabajo de Hugo Cores (1989: 198-199) refiere al reclutamiento de krumiros para sustituir obreros en la huelga de la empresa naval Regusci y Voulminot del año 1951, pero no avanza mucho más en su descripción.

Las fuentes consultadas para este trabajo registran la mirada de sus antagonistas, los trabajadores en huelga. Es claro que entre el personal que trabajó durante la huelga existieron, al menos, dos grupos: los trabajadores ya vinculados a la empresa y que no se plegaron a las medidas sindicales, y, por otro lado, los obreros contratados para sustituir huelguistas. Su ingreso y salida en camiones que los dejaban en un punto alejado de la fábrica [concretamente en el barrio de El Prado, que ya en la época era punto de intersección de múltiples líneas de transporte colectivo], denotaría que un número importante provenía de otras zonas de la ciudad lo que les evitaba sentir la presión social que se generaba en la zona de influencia de la fábrica.

44. Sobre la extensión del campo de la historia reciente véase Marchesi y Markarian (2012). Las tensiones entre libertad y orden como constitutivas de la democracia uruguaya en los años 60 en Rico (2005). 
Cores, Hugo (1989), La lucha de los gremios solidarios (1947-1952), Montevideo: EBO.

D'Elía, Germán (1969), El movimiento sindical, Montevideo: Nuestra Tierra.

- (1982), El Uruguay neo-batllista, 1946-1958, Montevideo: EBO.

Errandonea, Alfredo y Luis Costábile (1969), Sindicato y sociedad en el Uruguay, Montevideo: FCU.

Ferreira, Pablo (2014), "El otro viraje. Democracia y ciudadanía en el discurso de la lista quince ante los debates constitucionales de $1951 \mathrm{y}$ 1966", Contemporánea. Historia y problemas del siglo XIX, año $5, \mathrm{n}^{\circ} 5$, Montevideo, pp. 105-124.

Iglesias, Mariana (2011), "La excepción como práctica de gobierno en Uruguay, 1946-1963", en Contemporánea, Historia y problemas del siglo XX, año 2, $\mathrm{n}^{\circ}$ 2, Montevideo, pp. 137-155.

Leibner, Gerardo (2013), "La experiencia política de ASO (1948-1953): fracaso político e impulso a la renovación clasista de la izquierda uruguaya", en Contemporánea. Historia y problemas del siglo $X X$, año $4, n^{\circ} 4$, Montevideo, pp. 145-166.

Marchesi, Aldo y Vania Markarian (2012), "Cinco décadas de estudios sobre la crisis, la democracia y el autoritarismo en Uruguay", Contemporánea. Historia y problemas del siglo XX, año 3, n 3, Montevideo, pp. 213-242.

Masi, Hugo (1989), Vida de un metalúrgico. Reportaje a Rosario Pietraroia, Montevideo: Ediciones Pueblos Unidos.

Mendiondo, Dari (s/f), Gerardo Cuesta. Amigo - Compañero - Maestro, Montevideo: Tiempo de Cambio.

Porrini, Rodolfo (2005), La nueva clase trabajadora uruguaya (1940-1950), Montevideo: Departamento de Publicaciones de la FHCE.

Revel, Jacques (2005), "Micronálisis y construcción de lo social", en Jacques Revel, Un momento historiográfico: Trece ensayos de historia social, Buenos Aires: Manantial.

Rico, Álvaro (2005), Cómo nos domina la clase gobernante. Orden politico y obediencia social en la democracia posdictadura. Uruguay, 1985-2005, Montevideo: Trilce.

Rodríguez, Héctor (1966), Nuestros sindicatos, Montevideo: Centro Estudiantes de Derecho.

Ruiz, Esther (2007), "El Uruguay próspero y su crisis. 1946-1964”, en VV.AA, Historia del Uruguay en el siglo XX [1890-2005], Montevideo: EBO.

Sala, Lucía y Jorge Landinelli (1984), "50 años del movimiento obrero uruguayo”, en Pablo Gonzalez Casanova (dir.), Historia del movimiento obrero en América Latina, tomo IV, México: Siglo XXI, pp. 251-329.

Sapriza, Graciela (1993), Los caminos de una ilusión. 1913, huelga de mujeres en Juan Lacaze, Montevideo: Fin de Siglo.

Turianski, Wladimir (1973), El movimiento obrero uruguayo, Montevideo: EPU.

Wschebor, Isabel y Ariel Soto (2004), "El caleidoscopio de la huelga metalúr- 
gica de 1950", en Rodolfo Porrini (comp.), Historia y memoria del mundo del trabajo, Montevideo: CSIC-Udelar, pp. 89-104.

$$
* * *
$$

Título: Working resistance and employer violence in the "happy Uruguay" of the fifties. An approach from the strike in the metallurgical company Ferrosmalt.

Resumen: El artículo aborda el conflicto que enfrentó al sindicato con la patronal de la empresa metalúrgica Ferrosmalt en la ciudad de Montevideo durante el año 1955. La empresa, que había enajenado parte de sus acciones en manos de capitales extranjeros procuró incrementar los niveles de productividad y debilitar la organización sindical, enfrentando la resistencia de los trabajadores. En ese marco, se analizan un conjunto de episodios de violencia que se dieron durante el conflicto, especialmente a partir de que la empresa contrató nuevos trabajadores, formó un grupo armado para protegerlos y obtuvo apoyo de las fuerzas policiales. Estos episodios contribuyen a poner en discusión la imagen extendida y muchas veces idealizada del "Uruguay feliz" de los años 50.

Palabras clave: productividad - sindicato - empresarios - violencia - Uruguay

Abstract: The article discusses the conflict between the Union and employers of the metallurgical company Ferrosmalt in the city of Montevideo during the year 1955. The company, which had alienated part of its shares in the hands of foreign capital sought to increase levels of productivity and weaken the trade union organization, facing resistance from workers. In this context, discusses a set of episodes of violence that occurred during the conflict, especially from the company hired new workers, formed an armed group to protect them, and obtained support of police forces. These episodes will help put into discussion the extended image and often idealized the happy "Uruguay" of the 1950s

Keywords: productivity - unions - business - violence - Uruguay

Recepción: 26 de junio de 2015. Aprobación: 18 de mayo de 2016 . 